\title{
A review of factors influencing the utilization of eye care services
}

\author{
${ }^{*}$ Ntsoane MD and †Oduntan OA
}

*Department of Public Health, University of Limpopo, Turfloop Campus, P. Bag x1106, Sovenga, 0727 South Africa

$\dagger$ Discipline of Optometry, School of Physiotherapy, Sport Science and Optometry, University of KwaZulu Natal, Private Bag X54001, Durban, 4000 South Africa

$\uparrow<$ oduntanoa@ukzn.ac.za>

Received 3 August 2010; revised version accepted 17 November 2010

\begin{abstract}
Visual impairment (low vision and blindness) is a major health concern all over the world. Three main reasons for the high prevalence of visual impairment are non-availability, non-accessibility and non-affordability of eye care services. However, there are several factors that may act as barriers to the use of available, accessible and affordable eye care services. These include the lack of knowledge of the services, lack of knowledge of the possible impact of an eye disease and lack of knowledge of who to consult for management of eye diseases. Also, demographic, personal, social and cultural factors may influence or act as barriers to eye care
\end{abstract}

utilization. These various factors are reviewed in this article. Where there is poor utilization of available services, educational campaigns would lead to better understanding and promote greater utilization of eye care services. Early detection and management of eye diseases would reduce the burden of visual impairment and disability. Therefore, eye care providers and health care managers must have good knowledge of the various factors that would negatively influence utilization of eye care services and be responsive to them. ( $S$ Afr Optom 2010 69(4) 182-193)

Key words: Eye care utilization, eye care services, low vision, blindness

\section{Introduction}

Visual impairment can negatively impact on every aspect of life of an individual. Unfortunately, in many parts of the world, many people have low vision or are blind. In view of this, the World Health Organization (WHO) and the International Agency for the Prevention of Blindness (IAPB) with an international membership of Non-governmental Organizations (NGOs), Professional Associations, Eye care institutions and Corporations have developed a global initiative for the elimination of avoidable blindness by the year 20201 . The initiative called "Vision 2020: The Right to Vision" has three major components as target activities: Specific disease control, human resource development and infrastructure and appropriate technology development ${ }^{2}$. According to Lewallen and Courtright $^{3}$, major staff level development, infrastructure and community programmes will be necessary to achieve Vision 2020 goals. Fotouhi et $a l^{2}$ are of the opinion 
that the key factors in achieving the goals of Vision 2020 are eye care services and utilization. These imply that apart from manpower and infrastructure development, community programmes are needed to ensure utilization of eye care services.

In many parts of the world, most cases of blindness are preventable or manageable by surgery and or refractive error corrections ${ }^{3-8}$, however, the available resources cannot cope with the level of demand for eye care. This is because in many countries, eye care services are not readily available due to inadequacy of trained personnel or due to the fact that eye care practitioners are usually concentrated in the urban areas $^{8,9}$.

Refractive errors and eye diseases such as cataract, glaucoma, and diabetic retinopathy are common causes of visual impairment worldwide ${ }^{10}$. In Chile, for example, uncorrected refractive error accounts for $33 \%$ of those with vision under $6 / 18$ and only $36 \%$ of children with reduced acuity use spectacles ${ }^{11}$. Lack of awareness that causes of visual impairment are preventable, non-availability of accessible and affordable services are the main causes of blindness and visual impairment. Oduntan and Raliavhegwa ${ }^{12}$ found that only $39 \%$ of the respondents in a rural community survey in South Africa had their eyes examined within five years or more despite the accessible and affordable eye care services. Factors such as cost, lack of awareness, cultural beliefs and personal factors were identified as barriers to eye care utilization ${ }^{12}$. The poor utilization was highlighted as a concern because the time interval between eye examinations was high enough for certain avoidable or curable ocular diseases to cause irreversible visual loss or blindness.

\section{Factors influencing utilization of eye care services}

There are three primary factors namely, availability, affordability and accessibility of eye care services which could influence the prevention of visual impairment worldwide. Also, there are several secondary factors such as demographic, personal and socio-economic factors which may act as barriers to utilizing the available, accessible and affordable eye care services. According to Andersen ${ }^{13}$, health care services use is determined by societal, health service system and individual factors. Individual factors include the need, enabling factors, and predisposing factors. These various factors interact to influence the likelihood of an individual's utilizing health care services ${ }^{13,14}$. These factors can also apply to the use of eye care services. According to Keeffe et al ${ }^{15}$, utilization of eye care services can be explained by a combination of predisposing, enabling, and need characteristics. Enabling factors encompass family and community resources and accessibility to those resources. The predisposing factors are those that exist before an illness and describe the propensity of an individual to use health care services, and they include age, gender, marital status, race/ethnicity, occupation, beliefs (such as attitudes towards health services), knowledge about disease, and values ${ }^{15}$.

Individuals with eye problems or systemic conditions such as diabetes have a need for eye care services and would use them more frequently than those without perceived or diagnosed risk of eye problems. Therefore, they are likely to have higher utilization rate than those without perceived need. Enabling factors like health insurance, urban residence, living close to eye care service centres and language spoken can also influence the utilization of eye care services. Predisposing and personal attributes such as gender, family size, rural/ urban residence have been found to influence the utilization of eye care services. The primary and secondary factors which may act as barriers to eye care service utilization are discussed in this review article. Factors that may enhance utilization of the services are also briefly discussed. It is important for eye care managers and eye care providers to be conversant with the various barriers to utilization of eye care services, and prevent them.

Availability, accessibility and affordability of eye care services are important issues in the prevention of visual impairment. Obviously, a service that is not available rules out utilization. If the client lives very far from the available service, then the service may not be accessible to the patient, and if because of the long distance, the patient has to spend a large sum of money which he or she cannot afford; then the service is not affordable. This interdependence of availability, 
accessibility and affordability needs to be recognized in providing eye care services. Besides improving eye care infrastructure and manpower, a major challenge to eye care will be to address the barriers preventing a large proportion of the population from utilizing existing services ${ }^{2}, 16$. The ability to identify the factors affecting utilization of eye care services is important for policy makers, given the relationship between blindness and the postponement of timely eye examination, and the high social and personal cost associated with blindness ${ }^{17}$.

\section{Availability of eye care services}

Availability of eye care services varies from country to country in many regions of the world, and the number of eye care providers per millionpopulation in the richest countries may be nine times more than in the poorest countries ${ }^{11}$. Even within a country, availability of services may vary from province to province, from district to district, even from one community to another. Poor practitionerto-patient ratios, absence of eye-care personnel, inadequate facilities, poor state funding and lack of educational programs have been considered as the hallmarks of eye care in Africa, with preventable and treatable conditions being the leading cause of blindness ${ }^{18}$. Also, the disproportionate distribution of optometry and ophthalmological services between rural and urban areas in many developing countries may increase the rate of visual impairment in the rural areas.

Ophthalmological services are not available in many part of the Africa, and presumably in the rural areas of the developing countries. As at 2003, there were about five ophthalmologists in the Limpopo Province of South Africa, suggesting an estimated ophthalmology/ population ratio of 1:82 000. ${ }^{8}$ This means that blinding eye diseases such as cataract, glaucoma, and diabetic retinopathy cannot be managed on time, which may lead to low vision or even blindness. Poor people often rely on government hospitals for their eye care services including refractive corrections. However, in many countries, public hospitals do not have optometric services; therefore refractive conditions which could be corrected often lead to low vision and blindness.

Lack of trained personnel and infrastructure has been identified as barrier to refractive error corrections in Southern India ${ }^{19}$. Severe inadequate eye care services have been reported in Jamaica ${ }^{20}$. The total eye care provider/ population was only 2.04/100 000 and only 1.32/100 000 when optometrists are excluded. Over $43 \%$ of the population had never had an eye examination ${ }^{20}$. Obviously this will result in low utilization rate and high prevalence of eye and vision disorders. Non-availability of low cost, good quality low vision services and lack of experts or training to support services have hindered provision of low vision care services in the developing countries ${ }^{21}$. In Afghanistan, eye care services have been reported to be insufficient in quantity and quality 22 . The ratio of ophthalmologist to population has been estimated at $1: 200000$ and this inadequacy is compounded by poor distribution, there being $87 \%$ in the urban and $13 \%$ in the rural areas ${ }^{22}$. In Nigeria, non-availability of low vision devices in the country and lack of training in low vision were cited by ophthalmologists as major barriers to low vision care ${ }^{23}$. Wang and Javitt ${ }^{24}$ identified that fewer ophthalmologists was related to a lower rate of eye care use among elderly Americans with diabetic mellitus.

It should be emphasized, however, that nonavailability is not the only barrier to utilization of eye care services. According to Lewallen and Courtright ${ }^{25}$, cataract surgery coverage is low in many places for obvious reasons such as lack of trained manpower and supplies; even in places where services are available, there are many barriers which prevent patients from using the services. In countries like India, Brazil and Malawi, it has been shown that $33-92 \%$ of cataract blindness patients remain cataract blind, even when surgery is available ${ }^{25}$. Therefore, factors other than non-availability need to be considered in dealing with issues of poor utilization.

\section{Accessibility to eye care services}

Access to eye care service can be measured by the travel time required by public transportation to reach 
the nearest eye care provider ${ }^{11}$. Non-affordability and poor accessibility of the services have been identified as important causes of the high prevalence of blinding eye diseases ${ }^{11}$. According to Di Stefano ${ }^{26}$, the lack of accessible eye and vision care globally is a critical barrier to the successful elimination of avoidable blindness. People need access to preventative services that are effective in the prevention of disease or in the detection of asymptomatic diseases or risk factors at early, treatable stage ${ }^{26}$. In a part of the western Nigeria, the majority of eye care services are located in the urban areas and far from reach of the rural dwellers; therefore leaving many rural areas underserved. Consequently, people in the rural areas with avoidable and treatable eye conditions are largely unattended while city facilities remain underutilized ${ }^{27,28}$. This has resulted in many rural communities still relying on alternative sources of care including traditional healers and patent medicine sellers, who serve as frontline health workers ${ }^{27}$. A major barrier to eye care services in the rural areas of the world is poor conditions of the roads ${ }^{11,29,30}$ and this results in poor accessibility.

Difficulties in accessing good local optical services have been identified as one of the main barriers to spectacle use in Tanzania ${ }^{31}$. Also, in the Gambia, it has been reported that the most frequently identified barriers to uptake of cataract surgery was transportation difficulties and lack of an escort ${ }^{32}$. In Malawi, patients living near the district hospital have been found to be most likely to present to the ophthalmic assistance for eye care services ${ }^{33}$. According to Chandrasheka et al, ${ }^{34}$ one of the reasons for poor utilization of government facilities for eye care in India was the distance of the hospitals from rural villages. Similarly, Dhaliwal and Gupta $^{35}$ reported that the barrier to utilization of eye care services among cataract patients in India included distance from the hospital, or from the main road and lack of transport.

Issues relating to accessibility of eye care services are not peculiar to developing countries. In a study in Melbourne, Australia, O'Connor et al, ${ }^{36}$ reported that proximity and convenience were listed as main facilitators to eye care use and contrarily, issues relating to transport, needing an accompany person were barriers to utilization of low vision services. Wang et al ${ }^{37}$ reported that barriers to treatment of glaucoma and cataract among African American Medicare beneficiaries included limitations in access to the eye care system. Also, Gold et al ${ }^{38}$ reported that more than $5 \%$ of the USA population reported unmet need for eye glasses, presumably due to poor access. In a study of the perceived barriers to eye care and attitude among older black Americans, Owsley et al ${ }^{39}$ reported that the most frequently cited barrier by both the patients and eye care providers was transportation, suggesting that the eye care facilities are not easily accessible.

\section{Affordability of eye care services}

Affordability of eye care services is influenced by income levels and cost of the services. Robin et al 16 states that, in both the developing and developed nations, finances can definitely influence the utilization of ophthalmic health care. In many rural areas of the world, poverty is a major issue, hence residents are not able to afford the cost of eye care services and therefore conditions which could have been treated at an early stage are not attended to and may result in low vision and blindness ${ }^{10}$. According to Dandona et al $^{19}$, reasons for not utilizing eye care services may be personal or socioeconomic related.

Lewallen and Courtright ${ }^{25}$ reported that the cost of cataract surgery varies widely and in some places, it may be more than what poor people can afford. Also, in addition to the surgery, there are other costs such as transportation to the hospital, loss of work to the patient or to the caregiver accompanying the patient and living expenses for the carer while the patient is in the hospital25. According to Naidoo et al ${ }^{18}$, affordability of optometric services should be considered within a broader context than the cost of the spectacle because, even a free pair of spectacles could prove to be unaffordable, if the patient has to return to the clinic many times in order to collect it ${ }^{18}$. Prevalence of visual impairment is high in Ethiopia and eye care services utilization is limited, the main barrier has been attributed to the indirect costs of the services ${ }^{40}$. Habte et al ${ }^{41}$ suggested that indirect cost of surgery was one of the main barriers to uptake of surgical treatment for trachomatous trichiasis in the North of Ethiopia. Rabiu ${ }^{42}$ and Mpyet et al ${ }^{43}$ reported that cost was the most common reason for not seeking treatment for cataract in parts of Nigeria. Similarly, Nedgwa et al ${ }^{44}$ reported that lack of money was one of the main barriers to eye care use in Kenya; and in 
the Gambia, the most frequently identified barrier to uptake of cataract surgery was cost ${ }^{32}$.

Owsley et al ${ }^{39}$ and McGwin et al ${ }^{45}$ reported that one of the main barriers to the use of eye care services among elderly Americans was the cost. Schaumberg et al ${ }^{46}$, found that American women with high annual income were likely to have an examination within two years compared to women with lower income; and those with higher household incomes were particularly likely to have more frequent eye examinations. Elliot et al ${ }^{47}$ reported that the cost and having no insurance coverage for eye care were the two most commonly cited reasons why women with eye diseases do not visit an eye care provider. Owsley et al ${ }^{39}$ found that cost and lack of insurance were common barriers to eye care use among old black Americans. Zhang et al ${ }^{49}$ reported that Americans without health insurance had the lowest use of eye care services compared to those with health insurance. Possession of health care insurance and urban residence were also associated with greater use of eye care services 47,50 .

In Latin America and the Caribbean, affordability was found to be an important barrier to utilization of services by the poorest segments of the population ${ }^{11}$. In Trinidad and St. Vincent, the cost of eye care may be up to 15 days of salary; and in Honduras and Jamaica, it may be up to 30 days of salary or even more ${ }^{11}$.

Chandrashekhar et $a l^{34}$, found that the most common reason for not undergoing cataract surgery among patients with visual acuity less than $6 / 60$ in rural South India was inability to afford the operation. Similarly, Dhaliwal and Gupta ${ }^{35}$ found that barriers to the uptake of Surgery in India were related to cost and affordability. Also, Kovai et al ${ }^{51}$ found that among the visually impaired populations in the rural Andhra Pradesh, South India, about half cited economic reasons for not seeking treatment even after having noticed decreased vision. In Nepal, non-surgical expenses alone have been estimated to be one fifth of the annual income of a rural patient ${ }^{25}$ and Sapkota et al 52 identified finance as one of the barriers to uptake of cataract surgery in Gandaki Zone, Nepal. In Pakistan, cost was identified as a major barrier to cataract surgery uptake ${ }^{53}$. Palagyi et al ${ }^{29}$ reported that low utilization of eye care services among rural dwellers in Timor-Leste was inability to afford transport to eye care service centres. Affordability is therefore, one of the main barriers to eye care utilization.

\section{Factors influencing available, accessible and affordable services}

Where there are accessible and affordable eye care services, there are several factors that may influence utilization. In an Iran population, despite the available eye care services, there was under-utilization of available eye care services ${ }^{2}$. Over one third of a survey participants had never had an ophthalmic examination and two fifth of the visually impaired population never received any eye care service ${ }^{2}$. At some villages in India where there were eye camps, only $7 \%$ of people having eye problems go for eye care $^{54}$. In India, despite the relatively recent sustained eye care services that has seen a doubling of cataract output to 3.5 million in 2000; still more than $40 \%$ of those with bilateral blindness had never visited an eye doctor $^{16}$. Factors such as demography, knowledge, need and psychosocial problems influencing the use of available, accessible and affordable eye care services are discussed below.

\section{Demographic characteristics}

Age

In South India, Kovai et al ${ }^{51}$ found a significant association between age and noticeable decrease in vision and suggested that this might be due to the health seeking priorities in relation to age in rural areas, as age influences the decision to seek health. In a study among persons with glaucoma in rural South India, Robin et al ${ }^{16}$ found that the use of eye care increased significantly with age and this was attributed to the fact that most eye diseases manifest themselves during old age. Also, Schaumberg et al ${ }^{46}$ reported that the likelihood of using eye care services increased with advancing age due to the higher prevalence of disease such as diabetes, hypertension, cataract, and related maculopathy. Schaumberg et al ${ }^{46}$ reported that older American women were particularly likely to have more frequent eye examinations than younger ones. Other authors ${ }^{50,55}$ found an association between older age and utilization of eye care services and attributed this to old age health problems. 


\section{Gender}

Foutouhi et al ${ }^{2}$ reported that women in Iran were more likely to seek eye care services than men. Also, Palagyi et al ${ }^{29}$ reported that women in Timor-Leste with either low vision or blindness were more likely to seek treatment than men. Schaumberg et al ${ }^{46}$, Morales et al ${ }^{50}$ and Bylsma et al 56 also reported that women tended to have eye examinations more frequently than men. Wang and Javitt 25 found that older black American males with diabetes were less likely to use eye care services than women. These reports suggest that women are more careful about their eye health than men, hence gender has influence on eye care utilization.

\section{Race}

Orr et al 57 reported that black Americans were significantly less likely than white Americans to consult any type of eye care provider, and this was attributed to non-affordability of health care services to many of the blacks. Ganz et al ${ }^{58}$ found that black American children had lower levels of use of services and this was attributed to the fact that most of their parents did not have higher education and therefore, only earned meagre wages and hence fall below the Federal poverty level. Among American women, Schaumberg et al 46 found that, compared with the whites, Asian/Pacific Islanders were less likely, and blacks were more likely have eye examination within two years. Contrarily, Wang and Javitt ${ }^{24}$ reported that, among elderly Americans with diabetes, blacks were less likely to use eye care services than whites.

\section{Level of education}

Fotouhi et al 2 reported that the likelihood of seeking eye care in Iran was associated with higher levels of education. This relationship was attributable to greater knowledge and therefore, more reasonable behaviour. It was also presumed to be due to the fact that educated people are members of the higher socioeconomic class, thus may have greater access to the eye care services and find them more affordable. Barraza $^{17}$ reported a positive association between education and eye care use; the higher the level of education, the more likely and timely eye exams are performed, and the less likely that blindness will occur ${ }^{17}$. Schaumberg et al ${ }^{46}$ found a significant association between educational level and having an eye examination within two years among American women. Those with bachelor's degrees or master's degree were generally more likely to have had an examination than those with primary or high school level of training.

Morales et $a l^{51}$ and Orr et al ${ }^{57}$ found that people with higher education were significantly more likely to seek eye care services and this was attributed to the fact that most people with higher education were higher earners and could afford health care services. Among persons with glaucoma in rural South India, Robin et al 16 found that the use of eye care increased with increasing education ${ }^{16}$. Foran et al ${ }^{59}$ found that people with qualifications after high school were less likely to have uncorrected visual impairment. In a rural Andhra Pradesh study, Kovai et al ${ }^{47}$ found that the majority of rural population studied were illiterate and by definition blind (mainly due to cataract) and did not seek eye care services. This relationship was attributed to their lack knowledge of how to take care of themselves as most did not have higher education or were illiterates. Other authors $16,29,44,46,49,57$ found that level of education was associated with eye care utilization.

\section{Socioeconomic status}

Socio-economic status has been found to influence the use of eye care services. Zhang et al ${ }^{49}$ found that individuals with optional vision insurance and those with higher income levels were more likely to use eye care services. Robin et al 16 reported that the odds of using eye care increased significantly with the higher the income of the subject. Also, Schaumberg et al 46 found that women with annual income exceeding US \$50 000 were twice as likely to have an eye examination within two years as compared with women with lower income. Also, those with higher household incomes were particularly likely to have more frequent eye examination. Several other authors 34, 50. 57, 60-64 also reported that people with lower socioeconomic status are less likely to have eye examination. Foran et al ${ }^{59}$ found an association between eye care utilization, good job and possession of home. However, Latinen et al ${ }^{65}$ did not find such an association.

\section{Knowledge of eye diseases and eye care services}

If eye care services are available, affordable and 
accessible, and the services are not known to the target population, the services will not be used. O'Connor et $a l,{ }^{36}$ in a study carried out in Melbourne, Australia found that low utilization of eye care services was due to lack of knowledge of the available eye care services. Chandrashekar et al ${ }^{34}$, in a study on utilization and barriers to cataract surgical services in rural South India found that the reason for under-utilization of eye care services among the rural population was lack of awareness of the existing free-of-cost services offered by non-governmental organizations and low-cost eye surgical services. In a study of knowledge, attitude and practices regarding cataract surgery in parts of India, Bhagwan et al ${ }^{54}$ found that poor knowledge regarding eye diseases like cataract were reported and respondents were unaware of the possibilities to get their sight restored through operations.

In agreement with other studies, Farmer et al 66 in a study of rural/urban differences in accounts of patients' initial decision to consult primary care; reported that knowledge of where to get services and also who to consult have a big impact on eye care service utilization. In a study among persons with glaucoma, Robin et al 16 found that even though actual eye care was free, underutilization of the available eye care existed because patients were not aware they were free. Palagyi et al ${ }^{29}$ reported that rural dwellers were almost four times more unlikely to seek eye care than their urban counterparts due to lack of awareness of the available eye care service. In a rural community of South Africa, one of the reasons for underutilization of eye care services was lack of awareness of the services ${ }^{12}$. Other authors ${ }^{33,53}$ found that the most frequently identified barrier to uptake of cataract surgery was lack of information about the services.

Better education about prevention of blindness might help to minimize the prevalence of visual impairment. Schaumberg et al ${ }^{46}$, Palagyi et al ${ }^{29}$, Chandrashekar et al ${ }^{34}$, Bhagwan et al ${ }^{54}$ and Farmer et al ${ }^{66}$ have reported that knowledge of available eye care services increased the utilization of eye care services. Improving provider-patient interaction and developing public health messages about eye diseases and preventive eye care can facilitate increased use of appropriate eye care services. Muller et al ${ }^{67}$ found that following a public eye health campaign using the metropolitan and regional television, radio and newspaper in Australia, there was an improvement in the utilization of eye care services, especially by the people with diabetes. According to Courtright et $a l, 33$ men and women who either talked to someone about cataract surgery or knew another aphakic patients were more likely to accept surgery. Health education intervention must be designed specifically to increase awareness of symptomless diseases and to detect them at early stages ${ }^{28}$. Parental education and an enhanced school-based screening programme have been identified as necessary to address the unfilled need for refractive error correction among school-age children in China ${ }^{68}$. Kovai et al ${ }^{51}$ states that the predominance of personal reasons like lack of knowledge among respondents demonstrated that greater awareness regarding the importance of seeking treatment for visual impairment is needed to facilitate uptake of eye care services.

\section{Need}

There is a general consensus that utilization of eye care services varies with needs. Keeffe et al ${ }^{15}$ reported that the odds of using eye care services increased significantly with the presence of symptoms and general state of health. Schaumberg et al ${ }^{46}$ reported that the likelihood of using eye care services increased with the presence of eye problems like cataract, agerelated maculopathy, and systemic diseases like diabetes, hypertension, and rheumatoid arthritis. Patients with visual impairment and greater number of co-morbidities are more likely to seek eye care ${ }^{38}$. Palagyi et al 29 found that persons with gradual onset poor vision due to cataract or refractive error tended to be less likely to seek treatment than those with a more acute onset or painful problem, such as eye injuries. Latinen et al, ${ }^{65}$ found that people with moderate visual impairment (VA 0.1 to $0.25 \log$ MAR) were less likely to have received low vision rehabilitation, magnifying glasses, or other low vision devices compared with people with severe low vision ( $\mathrm{VA}<0.1$ ), even though they are more likely to benefit from optical low vision devices. This is because the need was greater among those with poorer vision. Fong et al ${ }^{69}$ found higher eye care utilization among older Australians, particularly those with correctable visual impairment. Similarly, Tay et al 70 found a relatively high need for, and high utilization rate, of eye care services in the subgroup of older Australians seeking aged care services. 


\section{Psychosocial factors}

Although blindness in most developing countries is preventable or curable $3-7$, barriers to usage are numerous and include social attitude and cultural beliefs $5,71,72$. Patel et al ${ }^{72}$ reported that social attitude towards visual health issues were the principal barriers to uptake of eye care services. Dhaliwal and Gupta ${ }^{35}$ reported that major barriers to eye care utilization were more related to patient's attitude such as 'ability to manage daily work in spite of the poor vision', 'cataract not matured', 'could see clearly with the other eye', and 'busy with work'. Other barriers were fear of surgery and possibility of surgery causing death. These barriers were reported more often than accessibility and $\operatorname{cost}^{35}$. In the Gambia, one of the most frequently identified reason for not undergoing cataract surgery was fear of surgery ${ }^{32}$.

According to Ashaye et al, ${ }^{28}$ many people, especially in the developing regions are still becoming blind due to barriers such as belief and attitudes. The authors ${ }^{28}$ found that beliefs and attitudes of the predominantly rural population are still major barriers to utilization of eye care services in Nigeria. In Canada, over one-third of the population still faces a situation of inequality and cultural differences between health providers and users. This has been identified as a major contributor to the underutilization of health services in the Canadian rural communities ${ }^{73}$. Chandrashekhar et al ${ }^{34}$, found that one of the most common reasons for not undergoing cataract surgery among patients with visual acuity less than $6 / 60$ in rural South India was fear of operation and the feeling that there was no need for such surgery. In some areas of India, strabismus (tropia or squint) was not considered treatable and was not considered related to loss of vision, in fact, it was considered a sign of good luck ${ }^{74}$. Majority of respondents in those communities also felt that children below four years should not wear spectacles; most did not feel that children's vision should be checked periodically. They felt that children's vision should be checked, only if the parents or care-taker felt there was a problem or if a child complained ${ }^{74}$. Palagyi et al ${ }^{29}$ also reported attitudinal reasons like 'feel there was no need for eye care services' was cited by greater proportion of participants in Timor-Leste.
Owsley et al ${ }^{39}$ reported that older African Americans do not make eye care a priority like other aspects of health and do not fully understand the importance of preventative strategies and available treatments. These attitudes were attributed to the fact that most of the older African-Americans were not literate and therefore, not knowledgeable of how best to care for themselves. In a study to examine knowledge, attitude, and beliefs about dilated eye examinations among African-Americans, Ellish et al 48 found that not having any symptoms and being too busy were part of the frequently mentioned reasons for not seeking eye care.

In South Africa, Oduntan and Raliavhegwa ${ }^{12}$ found that barriers to the use of eye care services in a rural community included traditional and personal beliefs about the western type of eye care services. The authors ${ }^{12}$ found that $5 \%$ of the study population would consult traditional healers for certain eye problems rather than seek eye care from the government hospitals even though, the public eye care services were readily available and affordable. The use of corrective spectacles was considered highly unconventional and was accompanied by fear of being ridiculed as being blind ${ }^{12}$. In Tanzania, peer pressure and parental concerns about safety of spectacle use were identified as barrier to spectacle use among secondary school children ${ }^{31}$. Also, criticism of the prescribing practices of local opticians and preference of alternative and traditional treatment for visual impairment were part of the main barriers to the use of eye care services ${ }^{31}$. Ignorance, personal attitude such as 'problems not causing much discomfort', 'did not bother', 'could manage', and 'accepted the condition' were the reasons for not seeking conventional eye care in a survey population in Kenya ${ }^{44}$.

\section{Perception}

Consumer satisfaction is an important factor in sustaining utilization of health care and it has been reported that dissatisfaction is a barrier to eye care utilization $^{28}$. It has been identified that one of the reasons for poor utilization of government health facilities in India was that the services at the primary health centres are provided by general nurses and these centres are usually not equipped to provide 
necessary services ${ }^{35}$. Palagyi et al ${ }^{29}$ also reported that in Timor-Leste, dissatisfaction with treatment was one of the barriers to eye care utilization, and satisfaction with treatment from private services was higher than that for government and expatriate service providers. Therefore, in addition to an increase in service quantity, there needs to be an improvement in intervention and service quality, to facilitate equitable, acceptable and effective eye care. The development, implementation and monitoring of standards of care and treatment/ clinical guidelines is one mechanism by which this may be achieved

\section{Others Factors}

Factors such as language barrier and poor systemic health have been identified as barriers to up-take of eye care services including low vision care $18,38,47,51$. Social engagement and lack of support may act as barriers to the uptake of eye care services. The main reasons for not having surgery for the treatment of trachomatous trichiasis in Northern Ethiopia included the burden of household tasks ${ }^{41}$ and one of the common reasons for not undergoing cataract surgery among patients with VA less than $6 / 60$ in rural South India was inability to find somebody to accompany the patient for the operation 35 .

\section{Conclusion}

There are many factors that may act as barriers to eye care utilization. Health care managers and professionals must be conversant with these factors. Eye care must be made available, accessible and affordable. Subsequently, factors that may act as barriers to their use must be identified and addressed. Routine planning for eye care services in rural areas must address the barriers to eye care perceived by the communities to increase the utilization of eye care services $^{51}$. Adequate publicity, patients' good perception and effective eye care team performance overall satisfaction can create awareness about the need to avail for eye care services ${ }^{75}$. In order to prevent avoidable blindness, eye care promotions and awareness on available eye care services must be done intensively and the implications of delayed eye care need to be emphasized. Attitudes and cultural factors need to be investigated in the rural communities and appropriate education provided, if low vision and blindness are to be reduced worldwide. Eye care providers must begin to educate individuals at an early age about the role of health care resources and how to better utilize them. People should be made aware that most vision problems can be corrected and blindness can be prevented by timely seeking eye care services.

\section{References}

1. World Health Organization (WHO). Elimination of affordable visual disability due to refractive errors. (WHO/ PBL/00.79). Geneva: World Health Organization, 2000.

2. Fotouhi A, Hashemi H, Mohammed K. Eye care utilization patterns in Tehran population: A population based cross-sectional study. Brit J Ophthalmol 2006 6-12.

3. Lewallen S, Courtright P 2001. Blindness in Africa: present and future needs. Brit J Ophthalmol 200185 897-903.

4. Brilliant GE, Brilliant LB. Using social epidemiology to understand who stays and who gets operated for cataract surgery in a rural setting. Soc Sci Med 198521 553-558.

5. Nwosu SNN. Beliefs and attitude to eye diseases and blindness in Anambra State, Nigeria. Nig J Ophthalmol 20021 16-20.

6. Frick KD. Foster A. The magnitude and cost of global blindness. An increasing problem than can be alleviated. Am J Ophthalmol 2003135 471-476.

7. Kluass V, Schaller UC. Tropical Ophthamological prevention and therapy. Vision 2020: The right to sight. Ophthalmol 2004101 764-765.

8. Oduntan AO, Nthangeni, ME, Ramudzuli, MR, Madu, SN. Causes and prevalence of low vision and blindness in black South African adults in the Limpopo province. S Afr Optom 200362 8-15.

9. Onyeluche CE. Constraints to optometric practice in the third world. J Am Optom Assoc 199364 710-715.

10. Oduntan AO. Global Visual Impairment: Epidemiology, implication and prevention. Polokwane South Africa. University of Limpopo, Turfloop Campus Press, 2005.

11. Silva JC, Bateman JB, Contreras F. Eye disease and care in Latin America and the Caribbean. Surv Ophthalmol 200247 267-274.

12. Oduntan AO, Raliavhegwa M. An evaluation of the impact of the eye care services delivered to the rural communities in the Mankweng Health sub-district of the Northern Province. S Afr Optom 200160 71-76.

13. Andersen R. Revisiting the behavioural model and access to medical care: Does it matter? J Health Soc behav 1995 36 1-10.

14. Bradley E. Health services research: Expanding the Anderson Model: The role of psychosocial factors in long term care use. http: // find articles.com/p/articles/mi-m 4149/is-537/ai-95105506/print/ tag,04/07/2008.

15. Keeffe JE, Weih LM, McCarty CA, Taylor HR. Utilization of eye care services by urban and rural Australia. Brit J Ophthalmol 200286 24-27.

16. Robin A, Nirmalayan P, Ramasamy K, Rengappa R, Katz 
J, Tielsch J, Ravilla D, Friedman M. The utilization of eye care services by persons with Glaucoma in rural South India. Trans Am Ophthalmol Soc 2004102 47-52.

17. Barraza J. The role of educational attainment in utilization of eye care services by Medicare recipients with diabetes mellitus. Medicare 199815 253-54.

18. Naidoo K, Savage B, Westerfall B. Creating a sustainable spectacle delivery solution. Vision 15 July/ August 2006.

19. Dandona R, Dandona L, Naduvilath TJ, McCarthy CA, Rao GN. Utilization of eye care services in an urban population in Southern India. Pradesh Eye disease study. Brit J Ophthalmol 200084 24-27.

20. Buchanan N, Horwitz SM. Health Policy and eye care services in Jamaica. Optom Vis Sci 200077 51-57.

21. Khan SA. Setting up low vision services in the developing world. Comm Eye Health 200417 17-20.

22. Husainzada R. Situation analysis of human resources in eye care in Afghanistan. Comm Eye Health 20072012.

23. Okoye OI, Aghaji AE, Umeh RE, Nwagbo DFE and Chukwu A. Barriers to the provision of clinical low vision services among ophthalmologists in Nigeria. Vis Imp Res 2007 9 11-17.

24. Wang F, Javitt JC. Eye care for elderly Americans with diabetes and failure to meet current guidelines. Ophthalmol 1996103 1744-1750.

25. Lewallen S, Courtright P. Recognizing and reducing the barrier to cataract surgery. Comm Health 200013 20-21.

26. Di Stefano A. The challenge of leadership for the new millennium. Am J Optom 200273 339-349.

27. Fafowora OF. Prevalence of blindness in rural ophthalmically underserved Nigerian community. West Afr Med J 199615 228-231.

28. Ashaye A, Ajuwon A, Adeoti C. Perceptions of blindness and blinding conditions in rural communities. $J$ Nat Med Assoc 200698 887-893.

29. Palagyi A, Ramke J, du Toit R, Brian G. Eye care in TimorLeste: a population-based study of utilization and barriers. Clin Exp Ophthalmol 200836 47-53.

30. Cochrane GM. Access, affordability and appropriate optometric eye care. S Afr Optom 199554 42-43.

31. Odedra N, Wedner SH, Shigongo ZS, Nyalali K, Gilbert C. Barriers to spectacle use in Tanzanian Secondary School students. Ophthal Epidemiol 2008 15 410-417.

32. Johnson JG, Goode SV, Faal H. Barrier to uptake of cataract surgery. Trop Doct 199828 218-220.

33. Courtright P, Kanjaloti S, Lewallen S. Barriers to acceptance of cataract surgery among patients presenting to district hospital in rural Malawi. Trop Geog Med 199547 15-18.

34. Chandrashekar TS, Bhat HV, Pai RV, Nair SK. Coverage, Utilization and barriers to cataract surgical services in rural South India, Results from a population based study. Pub Health 2007121 130-136.

35. Dhaliwal U, Gupta S. Barriers to uptake of cataract surgery in patients presenting to a hospital. Indian J Ophthalmol 200755 133-136.

36. O' Connor PM, Mu LC, Keeffe JE. Access and utilization of a new low vision rehabilitation. Clin Exp Ophthalmol 2008 36 547-552.
37. Wang F, Javitt JC and Tielsch JM. Racial variations in the treatment of glaucoma and cataract among medicare recipients. Ophththal Epidemiol 19974 89-100.

38. Gold D, Zufela B, Hodge WG. Perspectives on low vision in Canada: a pilot study. Can J Ophthalmol 200641 328354.

39. Owsley C, McGwin G, Scilley K, Girkin C, Phillips J, Searcey K. Perceived barriers to care and attitudes about vision and eye care: Focus groups with older African Americans and eye care providers. Invest Ophthalmol Vis Sci 2006 47 2797-2802.

40. Melese M, Alemayehu W, Friedlander E, Courtright P. Indirect cost associated with assessing eye care services as a barrier to service use in Ethiopia. Trop Med Int Health 20049 426-431.

41. Habte D, Gebre T, Zerihun, Assefa Y. Determinants of uptake of surgical treatment for trachomatous trichiasis in North Ethiopia. Ophthal Epidemiol 2008 15 328-333.

42. Rabiu MM. Cataract blindness and uptake of cataract surgery in a rural community of Northern Nigeria. Brit J Ophthalmol 200185 776-780.

43. Mpyet C, Dineen, BP, Solomon AW. Cataract surgical coverage and barriers to uptake of cataract surgery in leprosy villages of the North Eastern Nigeria. Brit J Ophthalmol 200589 936-938.

44. Nedgwa LK, Karimurio J, Okelo RO, Adala HS. Barriers to utilization of eye care services in Kibera slums of Nairobi. East Afr Med J 200582 506-509.

45. McGwin G, Khoury R, Cross J and Owsley C. Vision impairment and eye care utilization among Americans 50 years and older. Cur Eye Res 201035 451-458.

46. Schaumberg D, Christen W, Glynn R, Buring J. Demographic predictors of eye care utilization among women. Med Care 200038 638-646.

47. Elliot AF, Chou CF, Zhang X, Crews JE, Saaddine JB, Beckles GL, Owens-Gary MD. Eye care utilization among women aged 40 years with eye diseases in 19 states (20062008). Morb Mort Weekly Report 201059 588-591.

48. Ellish NJ, Royak-Schaler R, Higginbotham EJ. Knowledge attitudes and beliefs about dilated eye examination among African Americans. Invest Ophthalmol Vis Sci 200748 1989-1994.

49. Zhang X, Lee PP, Thomson TJ, Sharma S, Bake L, Geiss LS, Imperatore G, Gregg EW, Zhang X, Saaddine JB. Health insurance coverage and use of eye care services. Arch Ophthalmol 2008126 1121-1126.

50. Morales LS, Varma R, Paz SH, Lai MY, Mazhar K, Andersen RM, Azen SP, Los Angeles Latino Eye Study Group. Self-reported use of eye care among Latinos: Los Angeles Latino Eye Study. Ophthalmol 2010117 207-215.

51. Kovai V, Krishnaiah S, Shamanna BR, Thomas R, Roa GN. Barriers to accessing eye care services among visually impaired population in rural Andhra Pradesh, South india. Indian J Ophthalmol 200755 365-371.

52. Sapkota YD, Pokharel GP, Dulal S, Byanju RN, Maharjan IM. Barriers to uptake of cataract surgery in Gandaki Zone, Nepal. Kathmandu Univ Med J 20032 103-112.

53. Jadoon Z, Shah SP, Bourne R, Dineen B, Khan MA, Gil- 
bert CE, Foster A, Khan MD. Cataract prevalence, cataract surgery coverage and barriers to uptake of cataract surgery service in Pakistan. The Pakistan national blindness and visual impairment survey. Brit J Ophthalmol 200791 12601273.

54. Bhagwan J, Rastogi I, Malik J, Dhull C. Knowledge, attitude and practices regarding cataract surgery among severe cataract cases in Hanyana. Indian J Comm Med 200631 66-68.

55. Kuang TM, Tsai SY, Hsu WM, Cheng CY, Liu JH, Chou P. Correctable visual impairment in an elderly Chinese population in Taiwan: The Shipah Eye Study. Invest Ophthalmol Vis Sci 200748 1032-1037.

56. Bylsma GW, Le A, Mukesh BN, Taylor HR, Mccarty CA. utilization of eye care services by Victorian likely to benefit from eye care. Clin Exp Ophthalmol 200432 573-577.

57. Orr P, Barron Y, Schein OD, Rubin GS, West SK. Eye care utilization by older Americans. Ophthalmol $1999106905-$ 909.

58. Ganz M, Xuan Z, Hunter DG. Patterns of eye care use and expenditure among children with diagnosed eye conditions. J Am Assoc Ped Ophthalmol 200711 480-487.

59. Foran S, Rose K, Wang JJ, Mitchell P. Correctable visual impairment in an older population: the blue mountain study. Am J Ophthalmol 2002134 712-717.

60. Baker H, Murdoch IE. Can a public health intervention improve awareness and health seeking behaviour for glaucoma? Brit J Ophthalmol 200892 1671-1675.

61. Baker, R.S, Bazagarn, M, Bazagarn-Hejazi, S, Calderón JL. Access to vision care in an urban low-income multiethnic population. Ophthal Epidermiol 2005 12 1-12.

62. Liou HL, McCarthy CA, Jin CL, Taylor HR. Prevalence and predictors of under-corrected refractive errors in the Victorian population. Am J Ophthalmol 1999118 264-269.

63. Munoz B, West SK, Rodriquez J, Sanchez, R, Broman AT, Snyder R, Klein R. Blindness, visual impairment and problems with uncorrected refractive error in a Mexican-American population: Proyecto VER. Invest Ophthalmol 200243 608-614.

64. Thiagalingam S, Cumming RG, Mitchell P. Factors associated with under-corrected refractive errors in an older population: The Blue Mountains Eye Study. Brit J Ophthalmol 86 1042-1045.

65. Latinen A, Koskinene, S, Rudanko S-L, Martelin T, Laatikainen L, Aromaa A. Use of eye care services and need for assistance in the visually impaired. Optom Vis Sci 2008 85 341-349.

66. Farmer J, Iversen L, Campbell NC, Guest C, Chesson R, Deans G, Macdonald J. Rural /Urban differences in accounts of patients' initial decision to consult primary care. Health and Place 200612 210-221.

67. Muller A, Keeffe JE, Taylor HR. Changes in eye care utilization following an eye health promotion campaign. Clin Exp Ophthalmol 200735 305-309.

68. He M, Xu J, Yin Q, Ellwein LB. Need and challenges of refractive correction in urban chinese School children. Optom Vis Sci 200582 229-234.

69. Fong CS, Wnag JJ, Rochtchina E, Schneider J, Jakobsen
KB, Smith W, Mitchell P. Survey of effect on use of eye care by older persons with correctable visual impairment. Ophthal Epidemiol 200916 249-253.

70. Tay T, Rochtchina E, Mitchel P, Lindley R, Wang JJ. Eye care service utilization in older people seeking aged care. Clin Exp Ophthalmol 200634 141-145.

71. Fletcher AE. Low uptake of eye health in rural India. A cultural challenge of blindness prevention. Arch Ophthalmol 1999117 1393-1399.

72. Patel D, Baker H, Murdoch I. Barriers to uptake of eye care services in the Indian population living in Ealing, London. Health Educ J $2006 \mathbf{6 5}$ 267-276.

73. Pampalon R, Martinez J, Hamel D. Does living in rural areas make a difference for health in Quebec? Health and Place 200512 421-435.

74. Nirmalayan P, Sheeladevi D, Tamilselvi S, Victor A, Vijayalakshmi P, Rahmathulla L. Perception of eye disease and eye care needs of children among parents in rural South India: The Kariapatti Pediatric Eye Evaluation Project (KEEP). Comm Eye Care 20042 163-167.

75. Ayanniyi AA, Bob-Egbe S, Olatunji FO, Omolase CO, Omolade E, Ojehomon F, Edward MK. Social marketing potential of qualitative cost-free-to patient eye care programme in a Nigerian community. Ann Afr Med 20098 225-228. 